\title{
Zr solubility in silicate melts: Insights from X-ray absorption studies at high pressure and temperature with implications for mantle zircon
}

\author{
NICHOLAS FARMER ${ }^{1}$, TRACY RUSHMER ${ }^{1}$, ANTONY \\ BURNHAM $^{2}$ AND JEREMY WYKES ${ }^{3}$ \\ ${ }^{1}$ Macquarie University \\ ${ }^{2}$ Australian National University \\ ${ }^{3}$ ANSTO Australian Synchrotron \\ Presenting Author: nick.farmer@mq.edu.au
}

Zircon is an important accessory mineral in silicate rocks for geochemical and geochronological studies. The solubility of $\mathrm{Zr}$ in silicate melts has attracted significant attention, and experimental studies have established a strong dependence on composition [1], which is also linked to the coordination environment of $\mathrm{Zr}$ [2]. Generally, $\mathrm{Zr}$ is more soluble in melts in which a greater proportion of $\mathrm{Zr}$ has 8 -fold coordination.

We have conducted X-ray absorption spectroscopy experiments in situ at high pressure, high temperature conditions using the Macquarie D-DIA apparatus using a $\mathrm{Na}_{2} \mathrm{Si}_{2} \mathrm{O}_{5}$ $\mathrm{Mg}_{2} \mathrm{SiO}_{4}$ liquid composition. Additionally, we performed ex situ measurements on samples recovered from piston-cylinder experiments using a CMAS composition. Features of the $\mathrm{Zr} k$ edge white line change strongly with pressure in both series of experiments, and EXAFS analysis of the recovered sample suite shows that the relative intensities of these XANES features are linearly correlated with $\mathrm{Zr}-\mathrm{O}$ bond length and $\mathrm{Zr}$ coordination, which both increase from 0-5 GPa. The difference in coordination observed in CMAS melts in this pressure range is approximately equal to the difference in coordination between CMAS and the sodic compositions at ambient pressure.

Commonly used models of zircon solubility in silicate melts predict a large difference in zircon solubility between these two melt compositions. If zircon solubility is linked to the coordination environment of $\mathrm{Zr}$ then a similar variation in solubility may be expected with pressure, but this has not been observed in previous studies at pressures up to $2.5 \mathrm{GPa}$ [1]. As the magnitude of the change in coordination observed is $\sim 2.5$ greater from 2.5-5 GPa than from 0-2.5 GPa, we infer that $\mathrm{Zr}$ solubility in silicate melts is likely to change significantly in this higher-pressure range corresponding to Earth's upper mantle.

Experimental work is ongoing, but we anticipate that this will have implications for the stability of zircon in kimberlite or lamproite melts and partial melts associated with UHP metamorphism (e.g., Kokchetav), and the residence of zircon in the mantle in the presence of silicate melt.

[1] Boehnke, Watson, Trail, Harrison \& Schmitt, Chem. Geol., 351, 324-334.

[2] Farges, Ponander \& Brown Jr., Geochim. Cosmochim. Acta, $55,1563-1574$ 